\title{
The Use of Information Systems, and the Challenges of Transforming into a Knowledge and Information Society
}

\author{
Dr. Mostafa Hameed Al Taie \\ Associate Professor \\ Dr. Bilal Mohd Zakarneh \\ Assistant Professor \\ College of Mass Communication and Humanities \\ Ajman University \\ UAE
}

The research problem is summarized in the reasonableness of the opinions that prevailed in the intellectual, political and scientific circles that emphasize the technical inevitability as well as the technical inevitability that confirms the inevitability of entering the information society and then the knowledge society.

The industrial countries have developed their capacities and societies early on to accept and deal with these transformations, and developed comprehensive strategies for entering the information and knowledge society, which have allocated enormous budgets. Japan, for example, has developed a strategic plan since 1977 to transform itself into an information society with 65 billion dollars.

In spite of that readiness, these countries faced many problems. One would wonder how the case would be with the Arab and developing countries that are still lacking such readiness and did not prepare strategic plans for transformation, which will cause them to face complex problems?

Therefore, the idea of this research is based on the following assumptions:

- The transition to information and knowledge societies is an imperative. International communities have no choice but to deal with them and accept their effects.

- Any country that does not plan to accommodate the variables of change and change the course in favor of them will be subject to dependence, disintegration, or melting in other active and influential societies.

- The problems that will be imposed by the processes of transformation to information and knowledge societies will vary from one society to another. Therefore, each society must develop plans and treatments to solve its problems according to its values and civilization and its capabilities.

- The key to access the information and knowledge societies is the use of information systems methods related to informatics and education.

In order to verify the research assumptions, the following objectives were set:

- Identifying the information and knowledge revolution and getting to know its developments and potential effects.

- Identifying the nature of the problems that will result from the transformation of Arab and developing countries into information and knowledge societies.

- Exploring the method of technical information systems and the method of technical systems in education as a key to access the information and knowledge society.

The research adopted a descriptive approach to describe the problem of research, and analytical approach to analyze its dimensions and phenomena.

The research will address four major points:

The first is the revolution of communication and information as well as its implications in the information and knowledge society.

The second point encompasses the technical problems faced by Arab information and knowledge societies.

The third point addresses research in technical information systems and their importance to the knowledge society.

The fourth major point deals with the information systems and their role in the educational process in the knowledge society. 


\section{1- The revolution of communication and information and its implications in the information and knowledge society}

Communication is the nerve of contemporary life, described by some researchers in the nervous system of human societies, as human societies cannot connect and communicate without a communication network and civilized communication capable of containing the activities of modern societies.

The revolution of communication formed the spindle in which the industrial revolution and the revolution of information and knowledge revolves around, including the variables that entered all aspects of human life that are characterized by speed and inclusiveness. As a result of the communication revolution, the modern societies have been connected with each other in an accurate and sensitive network within comprehensive channels of communication. All of these have bridged distances and united many tendencies, trends, ideas and provided common symbols of human interaction among different societies. Moreover, they transformed the international community into a cosmopolitan village. Accessing the information society was not possible without the interaction between the revolution of communication, information and informatics, where the advancement of communication technologies has played a major role in the maturation of the information revolution and access to the information and knowledge society. These achievements have been embodied through mutual technical interaction and if we go back to the beginning of the technical revolution, we will notice that in the beginning of the twenty first century there had witnessed major transformations in the fields of communication and informatics,. We had seen the integration of the outcomes of the information revolution and the revolution of communication. As a result, new terms were coined which were not known to us previously. Examples of such terms are; the Information explosion: (to indicate the tremendous leap that has taken place in the field of communication and informatics). Information revolution included all fields of human activity and the transformation of knowledge production into a wide and complex industry, the most prominent of which was the disappearance of privacy and the influence of the international dimension on the outcomes of the means of communication and information. (1)

The most important potential impacts of the information and communication revolution can be summarized in the following points:

1. The development of communication from the phone to the Internet has left a significant impact on the lives of modern societies, especially in the areas of communication and education and that is called content revolution.

2. The impact of the revolution of communication and informatics increased the gap between those who possess information and techniques and those who do not.

3. The emergence of specializations aimed at the development of technology in an unprecedented manner.

4. A crisis emerged in the nature of media treatment of global issues.

5. The emergence of a major imbalance in the coverage of major international media of global issues.

6. The emergence of globalization and its negative effects on the structure of developing societies.

7. Media and communication were among the most useful to the technology revolution. This was reflected in the emergence of large-scale satellite broadcasting.

8. Technology and its successive developments have played a major role in the information revolution in modern societies. The effects of these developments have been reflected in the breadth of global information networks and the Internet with their multiple uses.

9. The extensive industrial development of communication devices has focused mainly on computers, related information and software that have become globalized.

10. One of the outcomes of the revolution of communication and informatics was a qualitative development in the collective consciousness and intellectual and cultural development that enabled the prevalence of selectivity among the public who receive the messages of the means of communication. We have witnessed the prevalence of phenomena of selective behavior, selective listening, selective observation and selective perception. (3)

11. Accessing ideas and information freely and without mediation of those who have been monopolizing the media for a long time.

12. The prevalence of phenomena of great diversity in programs that can be seen and followed, which means not depending on one party monopolizing the audio and visual production. 
13. Getting out of the isolation frame at the level of the individual and society to wider areas through communication and sharing knowledge.

14. The technical capabilities produced by digital television clearer images to the expansion of tasks and functions.

15. Providing the required information quickly and efficiently, which no one can impose restrictions on supervision and inspection.

\section{The technical problems faced by Arab information and knowledge societies}

There is a close relationship between the social environment and the technical environment, and the administrators and supervisors of the technical management must take into account the adaptation of the technical environment according to the standards and laws imposed by the social environment, because the industrial environment is the product of the social environment first and foremost.According to this perspective, civilized societies should not give more importance to technical calculations over human importance, and should not make man serve the machine, because such calculations would cause serious damage to human rights and lead to the disintegration of the value systems on which societies are based.The superiority of the machine over man in value will make man lose control of his social environment. When man loses his social values, human spirit and rights as a social being he will lose his need to the technology itself. Based on the above, the problems arising from the information and knowledge revolution can be summarized as follows: (4)

\section{Problematic imbalance among beneficiaries in knowledge and information societies.}

The information and knowledge society has been referred to in more than one place. Moreover, it has been defined in multiple perspectives, ranging from optimistic and pessimistic, skeptical and contemplative. Where it emerged from confirming the existence of this kind of societies and those who deny the existence of societies by this name. In addition, there are those who identified this label in a number of countries. Nevertheless, the trend that believes in the existence of the information society is limited to a number of industrialized and developed countries. The societies that emerged victorious from the Second World War witnessed the development of all areas of life, including technical, economic, scientific and cultural. These developments culminated in the emergence of the Information Society. Robert Taylor, Cronin and others insist that we live today in the information society, but they believe that the information society raises many reservations saying that international societies are not one level. The levels of development and the ability to manage technology and consumption of information. Some sources indicate that there are 12 countries, which constitute about $25 \%$ of the world population can be applied to the name of the information society, having more than $80 \%$ of the world's communication and information technologies: These countries are: Japan, USA, Germany, Canada, UK France, Sweden, Switzerland, Spain, Russia, Italy and the Netherlands. (5) Japan has developed a strategic plan since 1977 for the transformation into the information society. They set a budget estimated at $\$ 65$ billion. Moreover, these developments happened in unprecedented forms, with the aim of moving information societies to knowledge societies.

Knowledge societies move from the economy of goods and goods to the knowledge economy. This happens through the knowledge sector's control over the national income of knowledge societies. The national income of the knowledge economy in the United States is between $50-60 \%$ of the national income, and in European countries more than $40 \%$. Globally, the income of knowledge production has reached more than $£ 75$ billion since 1982 and this income increases by more than $12 \%$ annually. These developments will open new horizons for a world based on the knowledge economy, communication technologies, and information. (6)The knowledge economy today can be described as limited to the major developed countries. Developing countries are exposed to the negative effects of the information revolution, as they suffer from isolation and lack of cooperation of developed countries to benefit from the data of this revolution. It is possible to reach the conclusion that the elite of the information rich parties will have the power and influence. These developments will result in an increase in women's access to the labor market in knowledge societies and will force those who enter the labor market to possess technical skills that will enable them to perform future jobs.

\section{1- The problem of adapting technology in Arab and developing societies}

Every achievement in modern civilization has advantages and benefits, and at the same time has negative repercussions. Most of the negative effects on modern societies result from the misuse and manipulation of the vital resources produced by communication and information technologies. 
This requires communities entering the age of ICT to prepare the people of these communities to adapt and invest in technology according to their vital interests. However, this depends on the ability of societies to set conditions and controls that determine the ability of the individual to use technology and adapt it according to its circumstances, needs and basic interests. Technology and its uses, if left loose, may destroy the humanity of men, destroy its value system and disintegrate its social system. In this case the disadvantages become more than its benefits. It should be noted that despite the importance of technology, it added to the social problems of modern man, as it affected his values and beliefs. Therefore, these behaviors and their negative phenomena were called "the diseases of civilization". There are major differences between adjusting our social systems to technology and the adapting the technology to our social systems. The first condition requires us to abolish social values and dogmatic constants and transform our human spiritual behavior into material behavior governed by the machine. (7)

1- The problem of being able to keep abreast and absorbing technological developments.

The rapid scientific and technological developments and the widespread of industrialization have prevented many societies from keeping up with the new developments, and they made developing societies lose the capacity to absorb technology and its innovations, especially in the fields of education, information and media. To keep abreast of developments and to keep pace with progress requires the availability of material, scientific conditions and renewed technical expertise. For these reasons, the developing societies, especially the Arab ones, are experiencing a crisis that is more than one dimension. The most important indicators can be summarized in the following points: (8)

a. The lack of correlation between theoretical scientific preparation and applied practices in the field: This separation between academic studies and applied practices in the field of work and production indicates a clear imbalance that affects the accuracy of performance in most fields of production in most Arab and developing countries.

$\mathrm{b}$ - There is an indication that there is an imbalance between theoretical and applied studies in the fields of work, education and training leading to the tyranny of one of the practices on the other.

c. Lack of organization in the training levels: This imbalance is a manifestation of the lack of differentiation between the different training levels that commensurate with the levels of scientific qualification experience of the workers. There are some workers holding high and middle qualification and there are those with long experience of non-academics, therefore, it is wrong to combine all levels in one course.

d. The weakness of the educational and training curricula in the educational and training institutions. The weakness of the educational and training curricula is evident in all developing countries, especially in the Arab countries. The curricula of education and training have many implications, such as their dependence on indoctrination, as well as their lack of reliance on practical applications in the field...etc.

e. Another indicator is the absence of cooperation and coordination between educational institutions on the one hand and with the training institutions on the other. This leads to complex problems that are reflected on students in academic institutions by not being able to transform theoretical information into practical practices in the fields of work; they become strangers to the technology and find themselves overcome with a sense of fear and lacking self-confidence in dealing with modern technologies.

f. The training and development institutes do not rely on advanced scientific research centers: Among the most important dimensions of the media and informatics crisis in the Arab and developing countries is the lack of reliance on scientific research centers. This leads to confusion, randomness and copying. This leads to the weakness of performance methods. The solution to this problem lies in establishing a linkage between advanced research and scientific research centers and companies.

g. Lack of education, preparation and training: The various training and educational institutions suffer from the lack of many requirements of continuity and development, making them unable to cope with developments in the fields of science and technology.

h. Not connecting the university with community: this is why the educational institutions operate in isolation from the government institutions in the public and private sectors.

These results in the graduation of large numbers of students who cannot be accommodated in the workplace, because there is no plan and coordination between universities and state institutions regarding the admission policies in universities, which is conducted according to the plan, built upon the need of institutions in terms of numbers and disciplines. 


\section{Third point / Technical information systems and their importance to the knowledge society}

One of the most prominent outcomes of technical development in the information society was the emergence of information systems, where the information system is defined as: the expression of a set of principles, procedures, laws, and administrative activities and measures that ensure the flow of information in a society of modern societies. (9)

The development of information technologies has transformed into comprehensive high-definition networks, and that led to the World Wide Web that has become the main tool for the known and widespread information format in the contemporary world. However, a team of researchers and specialists in this field believes that the true cyberspace is today embodied by video and audio that can help in developing the science fiction.

The term Cyberspace and cybernetics derived from it in academia was accompanied by other developments in other areas such as the global village, which was used in the field of mass media and was used by famous figures such as Alvin Toffler. (10).

These terms confirm the technological determinism, which means: The progress of humanity is closely linked to electronic progress. This idea is based on the inevitability of the strong link between contemporary societies. The advocates of this trend tend to say that modern societies have no choice but to adapt these developments. (11)

As information systems are based on laws and procedures, they must be established under the following conditions:

a. Information systems should ensure that knowledge is disseminated to all.

b. States that adopt information systems must upgrade and expand their communication channels to ensure that information flows to all who need it.

c. It must be considered that information is not a national resource, but a common human heritage, based on the positive interaction communities and information institutions.

\section{Electronic Information Systems}

Since its inception, the information systems have been linked to the state as a political system that supervises the information systems and supports them towards the higher goals of society. Therefore, many countries have formed committees of specialists in information, libraries and documentation to develop legal frameworks and administrative structures, and define information systems policies that regulate the rights, duties and mechanisms of utilization, and determine the responsibilities and financial resources required to make the system at the national, regional and international levels.

\section{Objectives of the national information system}

The objectives are the basic justifications for establishing the system, where there is no system without clear objective goals at a certain level of importance, and on this basis the main objectives of the national information system can be defined as follows: (12)

a. Linking the various information centers and libraries that possess information holdings that serve researchers with each other and with scientific research centers, whether formal or informal, through a network of electronic medium. This network is linked to a central computer, managed under central supervision and control, with the aim of entering information and electronic organization centrally, to build an electronic database that includes information resources for the different channels involved in the system in order to provide diverse services to beneficiaries.

b. Developing a remote inspection strategy, through the portal, which facilitates the process of reviewing millions of pages of information and data stored electronically on the central database.

Distinguishing between information systems and information system

There are structural, organizational and procedural differences between the information systems and the information system.

The information systems are intended to minimize the procedures related to the library and information profession, in the light of the design of building national sources of information to enable the beneficiaries to benefit from the published titles.

In the light of this perception, information systems represent a narrower framework than the information system, which is intended to form a regulator consisted of sources of information, staff and users of the system from 
readers and researchers. The department of technology operates in the light of a system that makes it easier to take advantage of the information provided by the system and, accordingly, the system is the broadest framework of systems or subsystems. (13)

\section{System elements}

The components of the system or its main parts consist of complementary subsystems, i.e., they are composed of sub-functional elements. The part cannot function without integration with the rest of the elements. The elements of the system can be summarized as follows: (14)

a. Objectives of the system: The objectives of the system vary according to the functions it performs. The goal of establishing a production system, for example, is to convert raw materials into products for achieving certain profitability. The aim of the internal transport system in cities is to facilitate the movement of individuals and groups from one place to another within the city, and the objective of the information system is to provide information services to individuals and institutions covered by this system.

a. System inputs and outputs: The existence of a particular system in a specific environment necessarily necessitates the reception of certain inputs such as raw materials, data or documents to produce a particular output of the same type of input.

b. Treatment: Treatment is the most important component of the system, because treatment is considered as the heart that transfers inputs to outputs such as data and programs, etc.

c. Feedback: For all beings and creatures in the universe is a specific system, each system must have signal controller that control its performance.

d. Storage: vital information systems are characterized by their high capacity to store much more than their processed outputs, and storing in information systems either temporary or permanent.

\section{Information systems types}

Information systems use personnel and technical equipment in accordance with specific policies for the operation, collection, processing and distribution of information. Information systems are divided into the following sections according to their functions: (15)

1. Data Operating Systems: These systems are a mixture of manual and automated systems, involving computers and equipment based on one or more of the following operations:

a. Recording data and creating files.

b. Sorting files.

c. Merging files.

d. Making calculations.

e. Data and information storage.

f. Retrieving information and data.

g. Preparing copies of information and data.

\section{Management information systems}

Management information system is known as the composition that integrates data with their sources that provides information that will be used in management decisions. Thus, the operating data system is a vital part of the management information system. In addition, it is divided into human resource system, engineering information system, production information system, accounting system, marketing system, and costs system... etc.

These in subsystems are divided into other subsystems.
a. Calculate costs.
b. The payroll.
c. Primitive accounts.
d. Civilian accounts.
e. Fixed asset accounts.

\section{Computer-based information systems (C. B. I. S)}

The information system represents the internal sector of the enterprise. One chief function of this system is the possibility to avoid many negative effects such as:

1- Not accessing the data and information at the right time. 
2- Reducing errors that affect the accuracy of the data.

3- Cutting out paper storage methods that include shelves and cabinets.

4- Reducing the damage risk.

5- Reducing the cost, time, effort and money.

Enterprise information system features: Establishing an information system within the institutions reduces the problems and complexities facing enterprises, because enterprise information system has the advantages of serving the enterprise and adjust the system performance. The features of the system can be summarized as follows: - (16)

- Accuracy: The information system provides an advantage for all calculations required by the institution.

- Speed: Computer-based information system provides speed in data processing that is stemmed from the response accuracy of entries or processing system input.

- Achieving abundance in economic income: Storage operations in computer based information systems can yield big financial abundance when compared to manual method.

- Highly reliable capability: The system provides highly reliable capacity, when it is designed in accordance with clear methodology in order to establish an information system. The sole aim of this system is to serve researchers, scientists and decision makers, which makes this system trusted by the users.

- Achieving integral and accessing multiple search portlets: Multi search portlets are almost unattainable in traditional manual information systems, because adopting the manual systems increases the completion time significantly.

\section{Information systems analysis}

Every system in the universe has a life cycle starts from the date of its installation until it ends in a specific time. When the system becomes unable to perform its functions efficiently, an update in its structure is required and must be conducted in order to make work normally and efficiently. These updates are done according to studies and research which went under multiple phases and they can be summarized as follows:-

The first stage: the initial study, based on the following procedures:

a. Diagnosing and formulating the problem, and defining its framework accurately and explaining its causes.

b. setting the probability assumptions for solutions.

c. Conducting a feasibility study.

d. Providing a detailed report to senior management for appropriate decision-making.

The second phase is called the stage of analyzing the system and determining its requirements, or the comprehensive study and gathering the facts. This process is carried out by the following activities:

a. Providing needs and requirements.

b. Providing a comprehensive vision of the most appropriate solutions to the problem.

c. Submitting a detailed report to the senior management to make the appropriate decision. The decision is often pushed down to three main possibilities:

- Continuing the work of the project.

- Reviewing the project.

- Canceling the project and thinking about offering suitable alternatives.

The third stage: Conducting a feasibility study for the project in the event of a decision to continue it by the senior management.

The fourth stage: Designing the system and specifying the proposed qualities that should be in accordance with the following:

a. Reviewing the previous reports and studies.

b. Preparing the appropriate design for the system.

c. Preparing the physical design of the system.

d. Estimating the cost

e. Preparing a report to be presented to the senior management to take the appropriate decision regarding these procedures.

The fifth stage: Submitting the offers that include the following procedures:

a. Reviewing the design.

50 
b. Preparing the specifications booklet.

c. Examining and evaluating the offers.

d. Preparing a report on the appropriate offer to the senior management.

The sixth stage: It is called the implementation phase and it includes the following procedures:

a. Putting the plan into practice.

b. Selecting the appropriate programs for the plan.

c. Transforming or transferring to the new system

d. Reviewing the operation and treatment

e. Issuing follow-up reports.

Strategic tasks of the State to establish a national information network

Information network is considered as the circulatory system of the human body. It is not possible for a modern society to perform the functions of civilization without national information network supported by the latest technology. The national information network is based on two types of communication channels:-

a. Channels for personal contact with all it needs of preparation and maintenance.

b. Channels for mass communication with all it needs of techniques of high quality.

The national information network must be comprehensive covering the geographic map of society, and it should be supervised by national bodies that are technically, politically, intellectually and scientifically prepared technically to runs the network efficiently, fairly and objectively. The network should also have the ability to protect the public from harmful information. The government runs the national network; therefore, the government should do the following tasks:(17)

a. Scientific planning for the development of the information network and its communication channels through the development of comprehensive plans for the implementation of information systems as well as the technical and educational projects.

b. Coordinating among the research centers and centers of documentation and library services, to avoid repetition, and to develop and cooperate among the various institutions.

c. Advisory activities by providing advice to government agencies with anything that is related to information, services and the updated techniques.

National information network components are:

1- Organizational structure: taking the financial, administrative and legal tasks, as well as planning and strategizing.

2- The development and integration of resources and cooperation in helping to support and develop local resources.

3- Determining the focal points to ensure the distribution of roles and competences as well as the balanced geographical distribution.

4- Identifying the levels of services provided by the network to the beneficiaries in order to ensure the needs and distribution services on pivot points.

5- Knowing the main groups of beneficiaries, identifying responsibility, and offering information service for each group of beneficiaries within the network.

6- Developing a flexible system of communication that provides the possibility of dialogue and the ability to send messages and documents to beneficiaries.

7- Encoding: placing symbols and standard signals check mutual understanding for employees and beneficiaries.

8-Open a paper record that helps in identifying the places of the required material online.

9- Transferring: to ensure convergence and understanding within the network and transaction integration with other networks.

10-Developing criteria for evaluation and adjustment to achieve the effectiveness of different functions

11- Setting up training programs to direct beneficiaries and those responsible for running the network according to the applied information system, awareness of strategic plans and operational procedures.

The fourth point: method of systems and its role in the educational process in the knowledge society.'

\section{Defining the concept and functions of the system}


Webster Seventh New Collegiate Dictionary defines the System as "a regularly interacting or interdependent group of items forming a unified whole' or "a group of devices or artificial objects or an organization forming a network especially for distributing something or serving a common purpose a telephone system a heating system a highway system a computer system". Accordingly, the term system refers to a large number of things, from the smallest of an atom and the cell to the cosmic order.

In addition, the system as defined above is a set of interactive elements that made of complex curriculum, teachers, trainers and techniques that can correlate these components in an integrated system to achieve specific goals. (18)

The systems analysis approach focuses, according to (Romeo Fishki 1976), on three types of activities that can be summarized as follows: (19)

\section{1- System analysis:}

This part focuses on determining what system of inputs and outputs to achieve the community needs and goals of the learner, through precise system possibilities of human, financial and educational resources as well as the time and levels of learners in addition to identifying problems to be resolved or addressed.

\section{2- Planning to resolve the problem, and setting up the program:}

Planning means to identify possibilities for implementation in an in-depth study.

Therefore, this part focuses on identifying specific problem in a scientific and accurate way. This takes place alongside knowing the goals to be achieved and setting priorities in the program that make achieving objectives possible

\section{3- Implementation and correction:}

Implementation and correction are two processes that stand together inseparable in any business or scientific procedure. Implementation is inconsistent and does not achieve the desired objectives without a process to follow and check the correction. Therefore, the implementation and correction is one of the components of the system to be applied to the learning process as a whole.

Formal education planning models:

It is believed that educational institutions since its foundation had to answer four important fundamental questions revolving around the educational process as a whole. If these institutions develop correct and accurate answers and achieved integration among scientific notation, they can accomplish their educational goals, in which they will work on developing of the community. The four questions are as follows (20):-

1-What educational institution must accomplish of goals?

2-What activities learners do in the educational institution in order to achieve these goals? And what are the methods used to achieve this?

3- What educational conditions that enable the learner to do the activities?

4- What sources and individuals, facilities, materials and equipment are used in the activities to achieve these goals?

The people who are in charge of this process must conduct an analysis for the levels of students or learners before starting any design for the educational system. This analysis must answer the following questions:-

-What does the student know now?

-What should they know?

-What are the main educational problems?

-Is the student qualified for the proposed education?

-Does the student believes in the educational process, and has the desire and willingness to learn what they will learn?

Elements of educational system:

The educational system is one of these systems that is composed of elements that define its form, content and functions. Therefore, the basic elements of the educational system can be summed up by following points:(21) 
1 -Learners (students): students are considered as the most important element in the educational system. The students are the ultimate goal of every plan of education or training, and in that sense the teacher must learn to teach students the basic needs, especially in relation to their desires, abilities, motives and the limits of their abilities and potential.

2-Objectives: after studying and analyzing the actual realities of learners, we must take into account the planned systems method and the objectives that should be accomplished. In addition, the goals must be classified according to the nature of the system, whether educational, training or both.

3 -Conditions of learning: learning conditions are usually determined by temporal and spatial factors. Therefore, supervisors of the educational system select learning experiences and practices that help students achieve their goals successfully and accomplish educational excellence.

Teachers also select an education that fits the goals. They distribute students into large or small groups, or mass education in large halls equipped with technical devices.

4-Sources: they include all the services needed by the learner and which are provided to non-educational workers other than teachers and students. These sources include books, references, equipment, machines and teaching aids and facilities, etc.

5 -Outcomes: they include all the monitoring and supervising of operations and performance evaluation, in order to ascertain the degree of learning goals and improving, modifying, fostering the educational system by practical explanation systems.

Learning concept has evolved drastically in enabling teachers to use hardware and tools that are designed to improve the standards of learning and teaching. Educational technology exceeded its previous role as teaching aids, because these modern devices became highly developed.

\section{Conclusion}

Communication is the nerve of modern life and can be described as the nervous system of contemporary human societies. Human societies cannot connect and communicate without a sophisticated communication network capable of absorbing the activities of modern societies. The communication revolution formed the core that the industrial revolution and the revolution of information and knowledge revolving around. These variables were established for the formation of information and knowledge societies. However, access to the information and knowledge society was not possible without the interaction between the revolution of communication, information and informatics. The fields of human activity included the development of knowledge to a wide and diverse industry. The most important thing to note in this area is that there is a close relationship between the social environment and the technical environment. Thus, the supervisors of technology management in the Arab and Islamic societies should take into account the adaptation of the technical environment in accordance with the standards and laws imposed by the social environment, because, after all, the industrial environment is the product of the social environment.

According to this perspective, Arab societies should not prioritize the technical factor on human factor, and they should not make people in the service of the machine, because such treatment will cause serious damage to human rights and lead to the disintegration of value systems that underpin the Arab and Islamic societies. Societies have not prepared and developed national strategies to enter the information and knowledge society. Such societies are still limited to some advanced industrial societies, which adopted the economic input as the basis for accepting these transformations. Therefore, the knowledge economy can be described today as limited to the major industrialized countries. The developing countries are exposed to the negative effects of the information revolution because they are isolated and the industrial countries do not cooperate with them to benefit from the advantages of this revolution. The transformation into the knowledge economy is a risky road when it comes to Arab societies, because, despite the importance of technology, it has added social problems to modern man, as it has damaged its values systems, traditions and beliefs. The implications of social behaviors and effects require the following actions: -

1. Every Arab society should adapt technology to its social system rather than adapt its social system to technology.

2. The need to develop a national strategy to keep abreast of technological developments and assimilation.

3. Technical determinism requires the adoption of the methods of technical information systems, because it is the most important prerequisite for the transition to the information and knowledge society. 
4. The transition to an information and knowledge society requires the adoption of the systems approach in education, because this is one of the keys to access modern knowledge societies.

\section{References}

Dr. Mustafa Hameed Al-Taei, The Arabs and the Competence of Investing the Contradictory Roles of Media and Informatics, Journal of the First Scientific Conference of Human Sciences (Towards the Enrichment of Human Sciences), University of the 7th of April , Libya, 2009, pp. 3-4.

Dr. Yousef Abu Bakr, Libraries: A study of reality and a plan for the future, Tripoli, Academy of Graduate Studies, 2006, p. 118.

Milvin L. Devler Sandra Paul-Rockic. (Without a date). Theories of Media. Cairo: International House for Publishing and Distribution. P 277

Joseph N. peloton, global talk: the marriage of the computer, world communication and man, Brighton, Sussex: the harvester press, $1981 \mathrm{~m}, \mathrm{p} 166$

Dr. Younis Aziz, Technical and Information Management, Libya - Benghazi, Qar Younis University, 1994, p.15-16

Dr. Mustafa Hameed Al-Taei, Arabs and the Success of Investing the Contradictory Roles of the Media and Informatics, a previous source, pp. 15-16.

Ibid., P. 12.

Dr. Mustafa Hameed Al-Taei, Radio and Television Techniques and Their Importance in Teaching and Learning, Alexandria, Dar Al-Wafaa, 2007, pp. 117-141.

Dr. Abdul Hafez Salama, Information Services and Library Holdings Development, Amman: Dar Al-Fikr for Printing and Publishing, 1997, p. 12.

Osama al-Khuli, IT between intimidation and Underestimation. Journal of the Future, October 2000, p. 111.

Dr. Mustafa Hameed Al-Taei, Arabs and the Competence of Investing the Contradictory Roles of Media and Informatics, previous source, pp. 11-12.

Dr. Younes Aziz, Technical and Information Management, former source

Ibid, P.124

Dr. Mohammed Nabhan Sweilem, Information Systems. Cairo: The Academic Library, 1996, p. 15.

Ibid. P. 16

Ibid, P. 19

Dr. Abdul Hafiz Salameh, Information Services and Office Acquisition Development.Ibid P. 20.

Dr. Mustafa Hameed Al-Taei, Radio and Television Technologies and their Importance in Teaching and Learning, Ibid, Pp. 128.

Ibid., Pp. 128-129.

Ibid., Pp. 129-130.

Ibid., Pp. 131-132 